\title{
An Analysis of English Newspaper Articles Written by Iranian and Azeribaijani Journalists: Focus on Redundancy
}

\author{
Ghaffar Khamahani, Ilham M.Tahirov \\ Institute of Linguistics, Azerbaijan National Academy Of Sciences, Azerbaijan.
}

\begin{abstract}
One reason that EFL students are not successful readers concerning newspaper articles is that they are not familiar with redundancy in journalistic texts. The hypothesis is that articles written by Azerbaijani and Iranian journalists contain different amounts of redundancy. We selected 5 articles from Iranian newspapers and 5 from Azerbaijani ones and contrasted two sets of dada in terms of syntactic redundancy to find out which set is more redundant. The research indicates that the two sets of articles are more or less equally redundant in some categories but mote redundant in other categories.The outcomes of the study could be useful for both EFL learners and trainers. They might make their students familiar with the realizations of strategies employed by the writers.
\end{abstract}

Key words: Newspaper articles, Redundancy, Redundant Categories

Accepted Date: 21 May 2013

\section{Introduction}

It seems that one of the reasons that EFL learners are not successful readers in the FL newspapers is their not being familiar with text features. "Redundancy" is one of these features that is manifested in all levels of language including "syntax". Students being aware of the presence of this phenomenon, its realization and appropriate places in non-native texts, might have the chance of reading (and even writing) English texts as native speakers do .The main purpose of the present study is: (1) to identify possible realizations of syntactic redundancy, (2) to measure the frequency of those realizations in English newspaper texts written by Azərbaijani and Iranian journalists, and (3) to find out which group of texts are more redundant syntactically.

Pedagogical and linguistic implications will be discussed. As the study deals with contrasting two groups of newspaper articles in terms of redundancy, the design appropriate to the topic will be the analysis of the written mode of language, or what is called 'text linguistics'. So, I tend to compute the frequency of the realizations of syntactic redundancy in the two sets of data. Ten newspaper articles in different fields are selected from those two sets of newspapers (five articles by Iranian writers, and five by Azərbaijani writers).

\section{Background}

David crystal (1980) believes that a feature is redundant if it's presence is unnecessary to identify a linguistic unit. Kristine Marlmkjer (1991) argues that the features used in specific languages are not of equal significance; some are predictable from others. These predictable features are redundant. R.L.Trask (1993) defines redundancy as the phenomenon by which the same information is expressed more than once in a single sentence or utterance. Smith (1971) states that a feature is redundant if its presence is unnecessary. Goodman (1972) associates the efficiency of redundancy with reading comprehension. Horning (1979) identifies two major sources of redundancy: syntactic and semantic. Darian (1979) states that redundancy exists at all levels of language: from phonemes and spelling, words and affixes, through syntax, semantics, and discourse. In an unpublished paper that I found on the internet, Gillette and Witt (1998) express the absence of a proper definition on "linguistic redundancy". The definitions so far given for redundancy are incomplete, too simple, and often confuse the essence of redundancy with its function".

\section{Method of Research}

We can consider some of the items that are possible manifestations of syntactic redundancy. Among the modes of realizations of redundancy, I consider seven as the possible realizations of syntactic redundancy. Ten articles are selected for analysis from English newspapers published in Azerbaijan Republic and the Islamic Republic of Iran. The following table shows the source and the number of chosen articles from each newspaper (Table 1). 
Table 1: the Source and Number of Articles

\begin{tabular}{|rr|}
\hline Source & Number of Chosen Articles \\
Tehran Times & 5 \\
Bakusun & 3 \\
OUR CENTURY & 1 \\
THE AZORI TIMES & 1 \\
\hline
\end{tabular}

As I mentioned before, the seven possible realizations of syntactic redundancy are as follow: 1) Exact Repetition of Syntactic Elements: Sometimes the syntactic elements of a sentence are exactly repeated elsewhere in the text, either in the same role or in another role. Here is an example: Language death and language change are inevitable. Language, however, can be revitalized through many ways. It can be argued that when the more a syntactic element is repeated exactly throughout the text, the more syntactically redundant the text is.2) Repetition by Pronouns: Sometimes syntactic elements are not repeated exactly, but by means of pronouns (subject, object, possessive, reflexive pronouns): " The approach derives its roots from the notion of a theoretical model..."When a pronoun repeats a syntactic element preceding it, it actually reminds the reader of that element. Therefore, it can also be claimed that the more a text contains pronouns, the more syntactic redundancy there is in that text. 3) Repetition by Demonstratives: The demonstratives "this, that, these, and those" repeat different chunks of information already stated in the text, from a single word to a whole sentence:

" A long-standing claim concerning the relationship between language and culture ....is that ... This claim has led to..." 4) Repetition by the Article' the ': Occasionally, it is the article ' the ' that repeats the information already stated in the text. It is a reduced form of the demonstratives:" Data for the paper include....

Patterns in the data were identified through a grounded procedure... " 5) Repetition by Different Parts of Speech: Sometimes one syntactic element is repeated in the form of a different part of speech. Parts of speech include pronouns, nouns, verbs, adjectives, adverbs .Here is an example: "We examined mother's speech to 2-year-old children in both quiet and moderately noisy conditions.... Even more interesting was that many of the prosodic changes typical in IDS were accentuated in noise."

Here an adjective is repeated as a noun. 6) Grammatical Collocations: This category and the next one add to the syntactic redundancy of the text by increasing syntactic predictability of the sentence. When the first part of a grammatical collocation occurs in the text, the reader can predict the occurrence of the next part. It is believed that there are eight major types of grammatical collocations in English:

A) Noun + Preposition- e.g. ability in/at

B) Noun + to + Infinitive-e.g. a problem to solve

C)Noun + That Clause-e.g. We reached an agreement that

D) Preposition + Noun-e.g. On purpose

E)Adjective +Preposition-e.g. Tired of

F)Adjective +to + Infinitive-e.g. Easy to learn

G) Adjective + That Clause-e.g. She was delighted that...

H) Verb + Preposition-e.g. Believe in ..."

7) Correlative Conjunctions: Correlative conjunctions are two-word conjunctions that, like grammatical collocations, the occurrence of one predicts the occurrence of the other. These conjunctions include ' either... or..., neither... nor..., both... and..., between... and...

To sum up, I have considered seven categories as manifestations of syntactic redundancy:

- $\quad$ Exact repetition of syntactic elements (Category 1)

- $\quad$ Repetition by pronouns (Category 2)

- $\quad$ Repetition by demonstratives (Category 3)

- $\quad$ Repetition by the article ' the ' ( Category 4)

- $\quad$ Repetition by different parts of speech (Category 5)

- $\quad$ Grammatical collocations (Category 6)

- $\quad$ Correlative conjunctions (Category 7)

\section{Findings}

As the research represents, the most frequently occurring category in the articles written by Iranian journalists is the grammatical collocations-category 6 (123cases). On the contrary, the most frequently occurring category in the articles written by Azerbaijani journalists is " the exact repetition of syntactic elements-category 1(140 cases). Repetition by demonstratives and pronouns more frequently occurs in Iranian newspaper articles(57 cases). Repetition by article " the " more or less occurs with the same frequency(66 cases). Repetition by different parts of speech occurs more frequently in Iranian newspaper articles(75cases). Repetition by correlative conjunctions occurs neither in Iranian newspaper articles nor in Azerbaijani newspaper articles. 


\section{Conclusion}

We can conclude that, on the whole, the articles written by Iranian journalists contain more syntactic redundancy than the articles by Azerbaijani journalists. As argued by many authors, writing requires the writer to take the role of both reader and writer. Horning (1991:1) suggests that “... writing students can be taught to shift from a writer's perspective to a reader's". Doing so can help students understand important factors that make writing readable. Then she introduces redundancy and cohesion as two significant factors in 'readable writing .Widdowson (1984:49) has the same idea: "[the writer] has to enact an exchange whereby he anticipates the reaction of the addressee to what he says." He maintains that the writer performs two types of acts: focal and enabling acts; the purpose of focal acts is the expression of facts, ideas, views, etc. of writer and his initial purpose of writing, but enabling acts 'facilitate this conveyance'. Examples of enabling acts are justification and clarification- both of which to be samples of redundancy. While focal acts relates to the writer's role as addresser, enabling acts relates to his role as addressee and his reactions. This addressee, the writer assumes, will have certain kinds of knowledge including knowledge of linguistic rules.

Now, what is important is that the writer should neither over-estimate nor under-estimate this knowledge. If he over-estimates what the reader knows about linguistic rules, there will be under-redundancy in the syntax of his writing, and if he under-estimates reader's knowledge, he is performing over-redundancy in his message both of which, as discussed earlier, are undesirable. Davie (1995:18) suggests that when we teach students to recognize redundancy and ellipsis in what they read and write, we should not teach them to shun instinctively. Rather, we should try to teach them the difference between functional redundancy and needless redundancy, between expandable prose and expendable prose...". Amjadi parvar in his MA dissertation (2003:155) argues that writing skill cannot be taught; rather it should be acquired by the learners. Writing students should be engaged in appropriate tasks to improve their writings.

In order to make postgraduate or even graduate students familiar with the characteristics of English texts (one of those characteristics being 'redundancy' ), and help train them to write more native-like texts, one might design cloze-type or gap filling tasks that consist of these kinds of abstracts with the realization of syntactic redundancy being omitted. While doing these types of tasks, students get the chance of recognizing the places where English native writers make use of syntactic redundancy. In this way, they will gradually, think as native speakers do, and consequently, when they start to write themselves, their writing will be more native-like.

Davie (1990) argues that we should not teach our students to ask themselves, "Is there redundancy in my writing and how can I get rid of it ?" but rather, "Have I expanded or condensed my writing and repeated information at the appropriate places for my readers?"

If Iranian and Azerbaijani students are trained to write articles that are more acceptable from the viewpoint of standards of writing, they will have more opportunities to participate in academic communications.

In order to be 'academically literate', researchers should be conscious of rules and conventions that govern scholarly communication in their respective discourse community. 'Academic literacy is defined as the ability of producing and processing scientific information, or in general, communicating scientific information (Amjadi Parvar, 2003). Having gained the ability to write more native-like texts, Iranian and Azerbaijani students would be prevented from being 'consumers of knowledge produced in other countries'.

\section{References}

[1]. Amjadi Parvar, A. 2003, An Analysis of the Generic Structure of Abstracts of Research Articles in the Field of Applied Linguistics. MA Thesis, Tabriz Azad University

[2]. Asher, R.E.,1994, The Encyclopedia of Language and Linguistics (ed). Vol.7, Pergamon Press, London.

[3]. Bartlet, H.G., 1980, 'Rhetorical Redundancy in Apachean English Interlanguage' in International Journal of Human Communication.

[4]. Brown, G. and Yule,G.,1983, Discourse Analysis, CUP, London.

[5]. Cherry, C., 1957, On Human Communication. John Wiley and Sons, New York.

[6]. Corder, S. Pit, 1973,Introducing Applied Linguistics, Penguin Books,p.21.

[7]. Crystal, D.,1980, A Dictionary of Linguistics and Phonetics, Blackwell Publications, Oxford.

[8]. Darian, S., 1979, 'The Role of Redundancy in Language and Language Teaching' in System, Vol.7,pp.47-59.

[9]. Davies,A.1990,'The Role Redundancy in Language and Language Teaching in System ,Vol. 7,pp.47-59.

[10]. Davies ,A. ,1990 ,Principles of Language Testing , Basil Blackwel ,Inc. , London.

[11]. Falk , J., 1987,Linguistics and Language, John Willy and Sons, New York.

[12]. Gillette ,M and Wit ,C. 1998, What is Linguistic Redundancy?, internet :galton.uchicago.edu/ wit/ redundan.html-48k

[13]. Goodman ,K. S.,1973 ,Psycholinguistic Universals in the Reading process in F.Smith (ed), Psycholinguistics and Reading ,Holt, , Rinehart, and Winston ,New York.

[14]. Malrmker ,K.,1991, The Linguistics Encyclopedia ,New Fetter Lane ,London.

[15]. Smith,F ,1971,Understanding Reading :A Psycholinguistic Analysis of Reading and Learning to Read ,Holt k. , Rinehart, and Winston, New York.

[16]. Trask,R.L.1993,A Dictionary of Grammatical Terms in Linguistics, Routledge ,London.

[17]. Widdowson ,H.G.,1984,'Rules in Written Discourse' in Explorations in Applied linguistics 2, Oxford University Press, Oxford. 